\title{
Depression and marital satisfaction: the mediating role of sexual satisfaction and perceived partner acceptance in women after mastectomy
}

\begin{abstract}
BACKGROUND
Diagnosis and treatment of breast cancer disrupts women's functioning on both individual and dyadic levels. The main objective of the present study was to examine whether the partner's acceptance of the woman and her sexual satisfaction can play a key role in mediating the relationship between depression and marital satisfaction in women treated for breast cancer after mastectomy.
\end{abstract}

\section{PARTICIPANTS AND PROCEDURE}

The sample consisted of 97 women with breast cancer after mastectomy (mean age $=55.68$ years). The participants completed the following self-reported assessments: Beck's Depression Inventory, Scale of Assessment of SelfAttractiveness in the Relationship by Chybicka and Karasiewicz and the Good Marriage Questionnaire KDM-2 by Plopa and Rostowski. All women were married (89.70\%) or in informal relationships (10.30\%). Recruitment for the study was conducted among women from the Amazonki community.

\section{RESULTS}

The time since the first diagnosis and the commencement of surgical treatment was a negative predictor $(\beta=-.36$, $p<.001)$ of marital satisfaction in women with breast cancer after mastectomy, whereas acceptance by the partner was a significant positive predictor $(\beta=.30, p=.023)$; the mediation analyses showed that acceptance by the partner fully mediated the relationship between depression and marital satisfaction. Sexual satisfaction can also be considered as a significant total mediator between depression and marital satisfaction in women with breast cancer after mastectomy.

\section{CONCLUSIONS}

The results highlight the importance of the analysed variables for marital satisfaction of women with breast cancer and can serve as a helpful guide for clinicians and other health professionals. One of the more important findings concerned the importance of acceptance by the partner as a direct predictor of marital satisfaction. The research also showed that the women's conviction about their partners' acceptance and their sexual satisfaction renders their depression impactless in terms of marital satisfaction.

\section{KEY WORDS}

breast cancer; depression; marital satisfaction; partner acceptance; sexual satisfaction 


\section{BACKGROUND}

Breast cancer is the most commonly occurring malignant cancer both around the world (c.f. cancer statistics in the USA - Jemal et al., 2008) and in Poland (Stadnicka, Pawłowska-Muc, Bańkowska, \& Sadowska, 2014). Fortunately, the advances in breast cancer screening and treatment allow the survival rate to be increased (Gilbert, Ussher, \& Perz, 2010a; Siegel, Miller, \& Jemal, 2018), and patients suffering from this disease constitute the largest group of female cancer survivors (Fagundes, LeRoy, \& Karuga, 2015). For this reason, there is a growing need to conduct research on such problems as the quality of life and psychological well-being of women after breast cancer diagnosis (Reich, Lesur, \& Perdrizet-Chevallier, 2008) and the quality of married life, with special attention to changes to sexual functioning following diagnosis and treatment (Gilbert et al., 2010a). Undoubtedly, the two spheres of women's functioning, i.e. individual and dyadic, are strongly connected with each other. In the present article, attention is focused on investigating the relationship between the level of depression resulting from the great distress experienced by women treated for breast cancer and their marital satisfaction, as well as the mediators of this relationship.

Breast cancer diagnosis causes a number of disruptions in the sphere of psychological functioning due to the lowered sense of security caused by the risk of death, as well as by the method of treatment that violates bodily integrity (Manos, Sebastian, Bueno, Mateos, \& de la Torre, 2005; Fang, Chang, \& Shu, 2014). As a consequence of the disease, women are often subject to profound changes in perceived selfimage and in experiencing their own attractiveness (Pintado, 2017); moreover, changes to body image are considered a significant cause of distress (Hopwood, Fletcher, Lee, \& Al Ghazal, 2001; Izydorczyk, Kwapniewska, Lizinczyk, \& Sitnik-Warchulska, 2018). Strong emotions accompanying the fight against the disease and a sense of lack of control over changes that occur in the body as a result of the treatment may pose a threat to mental health (Heidari, Shahbazi, $\&$ Ghodusi, 2015). On the other hand coping with disease can sometimes lead to the post-traumatic growth in women after breast cancer surgery (Baglama \& Atak, 2015; Brix et al., 2013; Andysz, Najder, Merecz-Kot, \& Wójcik, 2015; Ogińska-Bulik, 2010). Numerous studies suggest that people with cancer might experience their diagnosis and treatment as traumatic (e.g. Cordova, Riba, \& Spiegel, 2017; Juczyński \& Ogińska-Bulik, 2009; Mehnert \& Koch, 2007; Ogińska-Bulik, 2010). Recurrent thoughts, memories and emotions that a woman cannot cope with, or a fear of relapse in particular, increase in some women the risk of post-traumatic stress disorder (PTSD) development. Breast cancer as a potentially traumatic stres- sor is often accompanied by negative outcomes such as depression and anxiety (Mehnert \& Koch, 2008).

Women undergoing mastectomy are particularly prone to experience difficulties. The loss of a breast is often experienced at the level of identity, provoking questions about femininity and self-esteem (Barthakur, Sharma, Chaturvedi, \& Manjunath, 2017). In a qualitative study carried out by Koçan and Gürsoy (2016), women after mastectomy spoke about the chronic feeling of defectiveness, lowering of their own perceived attractiveness, and experiencing a sense of embarrassment due to their appearance. The changed body image is a key factor lowering the quality of life, being a strong and negative predictor of self-esteem and emotional well-being of women (Brandt-Salmeri \& Przybyła-Basista, 2018; Pintado, 2017).

The distress caused by the disease may persist over time. Even up to two years after breast cancer has been diagnosed, approximately $20-30 \%$ of women still complain about chronic psychological and psychosexual problems (Bulsa, Rzepa, Foszczyńska-Kłoda, CzajaBulsa, \& Teichert, 2002). The diagnosis of breast cancer may also result in anxiety disorders and depressive reactions (Srivastava, Mumtaz, Anand, Shah, \& Meena, 2016; Boeding et al., 2014; Alacacioglu, Dirican, \& Yilmaz, 2013; Karabulutlu, Mehmet, Kerim, Salim, \& Ragibe, 2010). Usually, there is a gradual adaptation to the diagnosis, although in some patients anxiety and depression may last longer (Bulotiene, Veseliunas, Ostapenko, \& Furmonavicius, 2008; Stankiewicz, Radziwiłłowicz, \& Bidzan, 2011). Depression is one of the most common psychiatric disorders observed in breast cancer survivors (Su et al., 2017). The prevalence of depression varies from $5 \%$ to $40 \%$ (Su et al., 2017), with some researchers claiming depression among breast cancer sufferers to be underestimated (Zainal, Nik-Jaafar, Baharudin, Sabki, \& Ng, 2013), misdiagnosed and undertreated (Reich et al., 2008). Comparative studies of women after an invasive surgical procedure (i.e. radical mastectomy) and of women who did not undergo surgical treatment showed that despite the body image in both groups being disturbed, a higher level of depression was felt by women who did undergo mastectomy (Cordero et al., 2015). These results are also confirmed by other researchers, who indicate much higher scores on the anxiety and depression scale in women after mastectomy, compared to the group after breast conserving therapy (Kamińska et al., 2015). Women after radical mastectomy showed a tendency towards body hiding, as opposed to women after lumpectomy (Derbis \& Machnik-Czerwik, 2016).

The research shows that depression in women treated for breast cancer is associated with marital status (Bulotiene et al., 2008), although not all researchers confirm these results (Su et al., 2017). Conceptually different models have been proposed in the literature. Some authors suggest that the relationship between depression and marital satisfaction is bidi- 
rectional (Davila, Karney, Hall, \& Bradbury, 2003), whereas others claim that a low-quality marriage can lead to depression. For example, according to the marital discord model of depression developed by Beach, Sandeen, and O'Leary (1990), marital distress leads to an increased risk of depression by reducing available support, increasing hostility and criticism (see Rehman, Gollan, \& Mortimer, 2008). A model of this relationship is also used in the context of cancer. Rock, Steiner, Rand, and Bigatti (2014) find evidence that lack of marital satisfaction in women with breast cancer results in an increased risk of depression. Patients who felt their marriage was unsatisfactory were more likely to be distressed in the future compared to those who had a sense of marital satisfaction (Weihs, Enright, Howe, \& Simmens, 1999).

A third model suggests that depression predicts marital dissatisfaction (e.g. Coyne's interactional theory of depression - cf. Rehman et al., 2008). The analyses of the relationships between depressive symptoms and marital satisfaction were examined in the context of chronic disease (Pruchno, WilsonGenderson, \& Cartwright, 2009). Fowler and Gasiorek (2017) found that experiencing a higher level of depressive symptoms reported by women was associated with lower level of their own relational satisfaction and of their partners. Moreover, dysphoria (one of depressive symptoms) was negatively associated with engagement in relationship maintenance. Authors emphasise that without efforts to maintain relationships there is a risk of marriage deterioration (Fowler \& Gasiorek, 2017). A conclusion that depression had significantly negative effects on marital satisfaction was also reached by Renshaw, Blais, and Smith (2010) and Moyá, Prous, Fernández, and Alonso (2010). Interesting results obtained by Boostani, Hoseini, Khodadadi, and Froozi (2015) show a decrease in the level of marital satisfaction in the group of women after radical mastectomy in comparison with women after breast-conserving surgery.

Researchers agree that there is a negative relationship between depression and the assessment of family support (Su et al., 2017). Support from the partner is of particular importance here. The higher the perceived emotional support from the partner is, the lower is the level of depression (Talley, Molix, Schlegel, \& Bettencourt, 2010). For older women (over 55 years of age), important sources of support are both partners and their adult children who help them in the process of adapting to their condition and maintaining mental health (Maly, Umezawa, Leake, \& Silliman, 2005). Hagedoorn et al. (2000) proved the existence of a positive relationship between active engagement of the partner in providing support and marital satisfaction of patients suffering from various forms of cancer. The perception of the partner as being supportive promotes friendliness between spouses, leading to more constructive strategies for solving shared problems that are experienced more as "our problems" than each partner's personal ones (Boeding et al., 2014). The sense of closeness with the spouse is a fundamental factor in overcoming the cancer crisis (Koczwara \& Clark, 2003). The perceived support provided by the partner is a factor, in the light of the research, lowering the distress in the group of women with breast cancer (Bolger, Foster, Vinokur, \& Ng, 1996; Manne et al., 2004). According to Madhumanti and Sathiyaseelan (2014), women a year after mastectomy experienced greater satisfaction with the relationship, and showed better adaptation and fewer symptoms of depression and anxiety if their partner could adequately communicate their attachment, love, hope and compassion. This type of support strengthens the closeness of the partners and their satisfaction with the relationship and supports mutual understanding and care (Baglama \& Atak, 2015; Svetina \& Nastran, 2012; Brix et al., 2013).

Understanding the impact of cancer on close personal relationships is an extremely important research task because of the disease having an interpersonal context; the diagnosis and treatment has an impact not only on the patient but also on people who are significant to them, in particular the family (Thornton \& Perez, 2007). Analysis of the level of adaptation of patients and their partners to cancer shows a moderate positive correlation, which suggests the mutual influence of partners on each other (cf. Thornton \& Perez, 2007). Breast cancer and the invasive surgical procedure have a significant impact on the couple's functioning: mutual communication, sexual intercourse and the roles each of the partners play (O'Mahoney \& Carroll, 1997), the need to change the existing marital patterns of functioning and perform new family roles (Zimmermann, 2015). On the one hand, women diagnosed with breast cancer may experience numerous difficulties with psychosocial functioning (depression, anxiety, body image concerns, problems with the sexual sphere) and on the other hand, their partners may also reveal having difficulties with providing support as a result of their own distress and changes in their relationship (e.g. sexual difficulties, negotiating new roles and responsibilities: cf. Boeding et al., 2014).

Marital satisfaction is associated with the sexual functioning of married couples, and this suggests the importance of women's sexual adjustment to breast cancer and changes in the body resulting from treatment (Wimberly, Carver, Laurenceau, Harris, \& Antoni, 2005). Although most of the parameters describing the quality of life return to the state before the disease after about a year, the problems in experiencing one's own body, intimacy, communication with the partner and sexual life may endure (Rowland et al., 2009). Some women experience a reduced level of desire and general interest in sex (Gilbert et al., 2010a). Concentration on one's body during an intimate sexual relationship plays a very important role for healthy women as well (Wiederman, 2000). In contrast, in the
Depression and marital satisfaction in women after mastectomy 
group of women with breast cancer, the concentration is even more intense, especially in women who have experienced disfigurement of their breast, which is a symbol of femininity (Hopwood et al., 2000; cf. Wimberly et al., 2005). Some statistical data suggest that about $10-40 \%$ of patients with breast cancer have a negative sense of change in their relationships (cf. Rock et al., 2014). These observations validate undertaking research efforts aimed at determining the factors that have a significant impact on marital satisfaction during the fight with cancer.

Based on the review of the research results presented above, it can be assumed that one of the effects of breast cancer is lowered mood, and that there is a relationship between the depression in women treated for breast cancer and their sense of satisfaction with the relationship. Women's marital satisfaction is closely related to many factors, and in the context of breast cancer, many researchers emphasize the importance of the support provided by the partner. In the present research it was assumed that demonstration of acceptance by the partner is one of the ways of giving support that is (or should be) assessed as effective by women suffering from breast cancer, in that it positively affects their sense of satisfaction with the relationship. Sexual functioning in marriage seems to be the second variable important for women's marital satisfaction in the context of the struggle with breast cancer (Wimberly et al., 2005), with satisfaction assessment in this regard also playing an important role. Both of these variables can constitute factors modifying the relationship between the depression of women with breast cancer and marital satisfaction. Therefore, the main goal presented in our project was to analyse the relationship between depression, the time since the first diagnosis and the surgical treatment, the partner's acceptance of the woman, her sexual satisfaction and the marital satisfaction of women with breast cancer after mastectomy. The second aim was to investigate whether the partner's acceptance and the woman's sexual satisfaction mediate the relationship between women's depression and their marital satisfaction.

\section{PARTICIPANTS AND PROCEDURE}

The women in the study were recruited from the Amazonki communities throughout Poland. The data collection was conducted either face-to-face, or by mail or e-mail. The criteria of inclusion in the research group were the following: diagnosed breast cancer, history of mastectomy and being in a close relationship (marriage or cohabitation). A total of 275 questionnaires were distributed: 115 copies were distributed in the Amazonki communities, 140 copies were sent by mail, and 20 by e-mail. A total of 163 questionnaires were submitted; however, 66 of them were incomplete, incorrectly filled in or did not meet one of the criteria (34 women were single). Finally, the group was formed out of 97 post-mastectomy women who were married or in an informal relationship.

Participation in the research was completely voluntary. The examined women were informed about the purpose of the study and agreed to participate; anonymity and confidentiality were ensured. The study was approved by the Ethics Committee of the University of Silesia. The mean age of the surveyed women was 55.68 years $(S D=8.55)$. The most numerous group consisted of married women $(89.70 \%)$; the remainder lived in other informal relationships (10.30\%). The average relationship duration was 28.73 years $(S D=9.23)$. The vast majority of women had children (92.70\%). Most of the research participants came from large or medium-sized cities $(90.60 \%)$ and had secondary or higher education (76.20\%). A quarter of the surveyed women $(25.80 \%)$ were professionally active, and more than a half of the women $(61.80 \%)$ assessed their financial situation as good or very good. The majority of respondents $(75.30 \%)$ had been diagnosed with cancer and underwent treatment in the last 10 years (out of whom $41.20 \%$ had done so in the last 5 years). All the women had had a mastectomy: $74 \%$ of the women had finished a complete treatment and remain under supervision from an oncologist, $18.80 \%$ were undergoing chemotherapy at the time the research was conducted, and only a fraction of the women (7.30\%) were still in the middle of treatment.

The marital satisfaction of women in the investigated sample was relatively low $(M=113.01, S D=21.13)$, with $59.70 \%$ of the responses being above the mean value. The results were diverse within the group $(\min =53, \max =124)$. When comparing these results with the norms one can say they were located at a level of 4-5 sten. The average level of depression did not reach clinical values $(M=8.90, S D=7.40)$ and indicated a minimally depressed or non-depressed patient score but the range of the results was large $(\min =0$, $\max =34$ ). Almost $36 \%$ of the group exceeded a cut-off score of 11 points. These results suggest that some of the women experienced mild or moderate depression.

\section{MEASURES}

Participants completed a self-report questionnaire set comprising the Good Marriage Questionnaire (KDM-2), the Beck Depression Inventory, the Scale of Assessment of Self-Attractiveness in a Relationship and the Personal Information Form.

The Good Marriage Questionnaire KDM-2 by Plopa and Rostowski (Plopa, 2006) is used for measuring marital satisfaction and consists of 32 items (sample items: "As the years pass, the contact between us deepens, we feel more and more attached to each other", "We are unanimous when it comes to spending free 
time, weekends, vacation"). Respondents answered the statements on a 5-grade scale, ranging from 0 (I totally disagree) to 4 (I totally agree). This questionnaire is characterized by its high reliability (Plopa, 2006). The Cronbach's $\alpha$ reliability of the KDM-2 in the current study was .93 .

The Beck Depression Inventory (BDI) is used to measure depression. We used the Polish version of the BDI (Parnowski \& Jernajczyk, 1977). The BDI scale consists of 21 items. The subject chooses one of the four affirmative sentences describing the state of being and daily functioning. Each symptom is described using one of the alternative responses (with points assigned on the scale) depending on the severity of the depressive symptom from 0 (the symptom does not occur) to 3 points (the highest symptom severity). The sum of the points obtained in the assessment of individual symptoms is the numerical value of the so-called "depression level indicator" in the range of 0-63 points. In this version of the questionnaire, the lack of depression symptoms equals a score of 0 to 8 points (see Zawadzki, Popiel, \& Pragłowska, 2009). The higher the score, the more severe the depression is. In the present study, the reliability coefficient of the BDI was $\alpha=.87$.

The Scale of Assessment of Self-Attractiveness in a Relationship by Chybicka and Karasiewicz (2008) consists of 16 items rated on a 4-point scale from 1 (definitely yes) to 4 (definitely not). The scale is used to assess the sense of self-attractiveness in the relationship, general sexual satisfaction, own corporality and physical appearance. In the present study, two subscales were used: acceptance by the partner, signifying the sense of attractiveness in the eyes of the partner (e.g. "My partner accepts my defects"; "I do not feel attractive to my partner") and sexual satisfaction meaning lack of inhibitions associated with experiencing sexual pleasure (e.g. "Sexual intercourse with my partner is satisfying to me", "I do not enjoy sex at the moment"). In the present study, Cronbach's $\alpha$ coefficient for the first subscale (Acceptance by the partner) was $\alpha=.75$, and for the second subscale (Sexual satisfaction) $\alpha=.70$.

Personal Information Form. This form consists of questions regarding sociodemographic data (e.g. age, education level, employment status, type of intimate relationships: marriage or informal relationships) and basic clinical information (history of breast cancer, history of medical treatment, current physical condition).

Statistical analysis (regression and mediation analysis) was performed using PS IMAGO 5 SPSS 23.

\section{RESULTS}

\section{PREDICTORS OF MARITAL SATISFACTION OF WOMEN WITH BREAST CANCER}

Based on the above state-of-the-art analysis it was assumed that the predictive role for women's marital satisfaction in the context of breast cancer can be attributed both to objective factors (e.g. time since the surgical treatment) and subjective ones (depressive symptoms, sexual satisfaction, feeling of partner's support and acceptance). Stepwise regression (forward selection model) was used to determine which of the four factors (time since the first diagnosis and the commencement of surgical treatment, depression, acceptance by the partner, woman's sexual satisfaction) are predictors of marital satisfaction in women with breast cancer after mastectomy. The results of the analysis are shown in Table 1.

Table 1

Predictors of marital satisfaction of women with breast cancer after mastectomy

\begin{tabular}{|c|c|c|c|c|c|}
\hline Variable & $B$ & $S E$ & $\beta$ & $t$ & $p$ \\
\hline \multicolumn{6}{|l|}{ Step 1} \\
\hline Time since first diagnosis and surgical treatment & -8.91 & 2.48 & -.35 & -3.60 & .001 \\
\hline \multicolumn{6}{|l|}{ Step 2} \\
\hline Time since first diagnosis and surgical treatment & -9.48 & 2.70 & -.37 & -3.52 & .001 \\
\hline Depression & -0.69 & 0.27 & -.24 & -2.55 & .013 \\
\hline \multicolumn{6}{|l|}{ Step 3} \\
\hline Time since first diagnosis and surgical treatment & -9.23 & 2.55 & -.36 & -3.63 & .001 \\
\hline Depression & -0.07 & 0.30 & -.02 & -0.23 & .818 \\
\hline Acceptance of woman by partner & 2.70 & 1.17 & .30 & 2.31 & .023 \\
\hline Woman's sexual satisfaction & 1.08 & 0.94 & .15 & 1.15 & .254 \\
\hline
\end{tabular}

Step 1 - statistics of the model: $R^{2}=.12$, adj. $R^{2}=.11, F=12.93, d f=1, p<.001$

Step 2 - statistics of the model: $R^{2}=.20$, adj. $R^{2}=.17, F=5.74, d f=4, p<.001$

Step 3 - statistics of the model: $R^{2}=.32$, adj. $R^{2}=.27, F=6.74, d f=6, p<.001$ 
The statistical significance of the assumed model was confirmed by the results of regression analyses. The independent variables of the model accounted for approximately $27 \%$ of the total variance of the dependent variable. Three-step regression analyses were employed, where time since the first diagnosis and the commencement of surgical treatment (as a control variable) was entered as the first step; depression was entered as the second step; and in the third step, both acceptance by the partner and woman's sexual satisfaction were entered simultaneously. For the entire group of women with breast cancer after mastectomy, time since the first diagnosis and the commencement of surgical treatment was the most significant predictor of marital satisfaction $(\beta=-.36$, $p<.001)$. Acceptance by the partner $(\beta=.30, p=.023)$ was the second significant predictor. The other variables, i.e. depression and woman's sexual satisfaction, were found to be statistically insignificant.

\section{THE MEDIATING ROLE OF PERCEIVED ACCEPTANCE BY THE PARTNER}

In order to examine whether acceptance by the partner mediates the relationship between depression and marital satisfaction in women with breast cancer after mastectomy, mediation analysis was used. It was conducted in accordance with Baron and Kenny's approach (1986). The first step of the mediation analysis confirmed that depression predicted marital satisfaction of women $(\beta=-.23, p=.023)$. The second step of the analysis proved a negative relationship between depression and the potential mediator - acceptance by the partner $(\beta=-.45, p<.001)$. In the third step, it was found that acceptance by the partner (a potential mediator) was associated with marital satisfaction $(\beta=.40, p<.001)$. When acceptance by the partner was included in the regression equation, the $\beta$ weight for depression became statistically insignificant for marital satisfaction (see Figure 1). Consequently, the role of depression in predicting marital satisfaction decreased. In other words, the mediation analysis showed that acceptance by the partner fully mediated the relationship between depression and marital satisfaction. The outcome of the Sobel test was statistically significant $(Z=-2.61, p=.009)$.

\section{THE MEDIATING ROLE OF SEXUAL SATISFACTION OF WOMEN}

In order to test whether sexual satisfaction mediates the relationship between depression and marital satisfaction in women with breast cancer after mastectomy, we conducted mediation analysis in accordance with Baron and Kenny's approach (1986). The first step of the mediation analysis confirmed that depression predicted marital satisfaction of women $(\beta=-.23$, $p=.023)$. The second step of the analysis proved a negative relationship between depression and the potential mediator - sexual satisfaction of the woman $(\beta=-.45, p<.001)$. In the third step, it was found that sexual satisfaction of the woman (a potential mediator) was positively associated with marital satisfaction $(\beta=.41, p<.001)$. When sexual satisfaction of

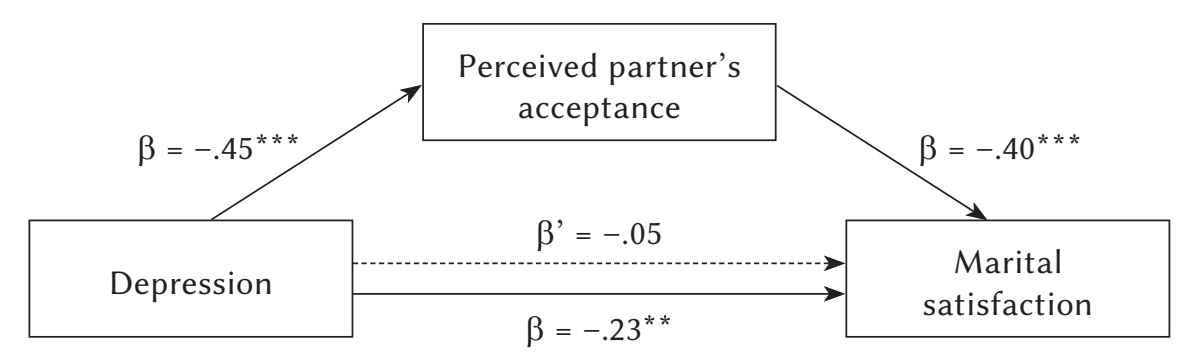

Note. ${ }^{*} p<.05,{ }^{* *} p<.01,{ }^{* * *} p<.001$

Figure 1. Perceived partner's acceptance as a mediator between depression and marital satisfaction.

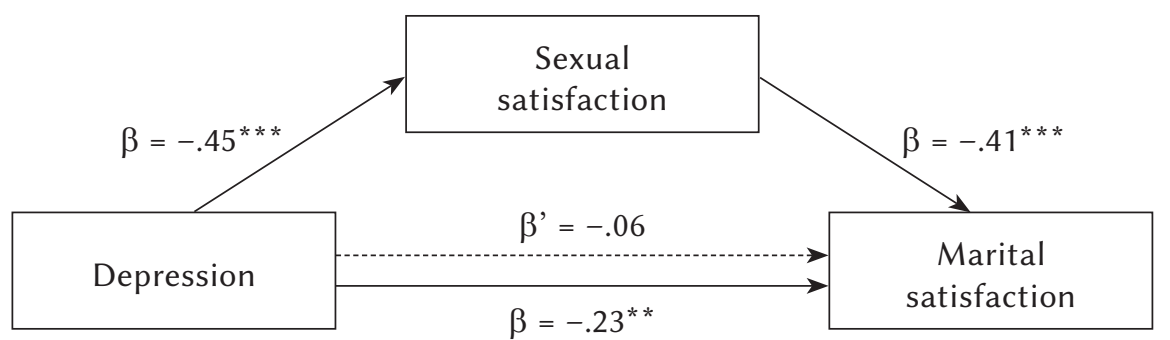

Note. ${ }^{*} p<.05,{ }^{* *} p<.01,{ }^{* * *} p<.001$

Figure 2. Sexual satisfaction as a mediator between depression and marital satisfaction. 
the woman was included in the regression equation, the $\beta$ weight for depression became statistically insignificant for marital satisfaction (see Figure 2). The mediating effect was total: sexual satisfaction can be considered a significant total mediator for the relationship between depression and marital satisfaction in women with breast cancer after mastectomy. The mediation effect was statistically significant according to the Sobel test $(Z=-2.41, p=.015)$. A graphic representation of the results is shown in Figure 2.

\section{DISCUSSION}

Our research confirmed the significant role of the partner's acceptance in shaping marital satisfaction in women with breast cancer after mastectomy. The acceptance that the women experienced was, on the one hand, a direct positive predictor of marital satisfaction, and on the other hand, acted as a mediator for the relationship between women's depression and their marital satisfaction. Our findings are confirmed by the reports of many researchers who point to the relationship between the perception of the partner's support and sexual adjustment and overall satisfaction with the relationship in the group of women with breast cancer (Kinsinger, Laurenceau, Carver, \& Antoni, 2011). The partner's display of support in marriages struggling with cancer has a positive effect on intimacy in the relationship (Li \& Loke, 2014). According to Wimberly et al. (2005), the perception of a man's reaction to a woman's attempts to deal with the situation is of great importance for a close relationship. Women who see their partners as empathetic, emotionally connected to them and sexually interested in them show a higher level of psychosocial and psychosexual adjustment. A positive relationship was observed between the partner's active engagement in providing support and the marital satisfaction of patients suffering from various types of cancer (Hagedoorn et al., 2000). A review of the literature (cf. Helgeson \& Cohen, 1996) indicates that what cancer patients desire the most is emotional support and the availability of someone with whom they can talk about their fears and concerns. There is also the strongest association between this type of support and adjustment to the disease. Helgeson and Cohen (1996) suggest five mechanisms by which social support can influence the process of psychological and physical adjustment to cancer: enhancement of self-esteem, restoration of perceived control, instilling optimism about the future, giving meaning to the experience and emotionally supporting the patient. Support may consist in lowering the pressure or changing the perception of the situation and of oneself by the person assisted (Cohen \& Wills, 1985).

We assumed the feeling of being accepted to be the proof of a woman experiencing emotional sup- port from her partner. According to the definition adopted by Chybicka and Karasiewicz (2008), acceptance is associated with the sense of being attractive to the partner in a romantic relationship, which is particularly important in the context of breast cancer and the need to face the effects of the mutilation of a woman's body. The feeling that the partner not only accepts the defects but also that the woman may feel accepted and attractive to the partner has a positive impact on her self-esteem (see conclusions from the research by Helgeson \& Cohen, 1996). In addition, this kind of emotional support helps to relieve depressive symptoms and improves the quality of the relationship (Stephanson, Delongis, Esdaile, \& Lehman, 2014). Such a direct relationship between the sense of acceptance by the partner and the marital satisfaction of women has been definitely demonstrated in our research. Moreover, the sense of acceptance by the partner played the role of a total mediator of the relationship between depression in women (as a result of chronic stress) and marital satisfaction. This means that thanks to the support received from the partner, conducive to the development of the sense of being accepted, symptoms of depression in women are reduced to such an extent that they no longer have a significant negative impact on the feeling of marital satisfaction. One of the biggest concerns of women after mastectomy is the fear of being rejected by the partner or reluctance on his part (Avci \& Kumcagiz, 2011), whereas the support displayed by the partner is associated with lowering the level of women's depression (Su et al., 2017; Talley et al., 2010).

The sense of acceptance by the partner is linked to sexual satisfaction, which is particularly important in the context of mastectomy. In our research, sexual satisfaction, as well as acceptance by the partner, acted as a total mediator for the relationship between women's depression and their evaluation of marital satisfaction. This means that by feeling sexual satisfaction associated with experiencing sexual pleasure, lack of inhibition or sense of embarrassment, the symptoms of women's depression decrease to such an extent that they cease to have significant negative significance for the marital satisfaction of women. Emotional support from the partner is undoubtedly associated with better sexual functioning of women with breast cancer in the post-operative period and, as research shows, it is a strong predictor of satisfaction from the relationship and sexual well-being (Kinsinger et al., 2011). Our results are in line with the almost universally perceived need to explore the intimate life of female cancer survivors (Gilbert et al., 2010a; Ghizzani, Bruni, \& Luisi, 2018). It is a very important sphere of functioning that affects an individual's quality of life and the quality of the intimate relationship (Ghizzani et al., 2018). Breast cancer is, on the one hand, an individual disease, but on the other hand, it is a disease of the dyad (Zahlis \& Lewis, 2010).
Depression and marital satisfaction in women after mastectomy 
And while the most important thing during intensive cancer treatment is to secure the woman's survival (and sex is not a priority), when time passes, sexuality and intimacy become more important both in the life of the woman and the couple (Ghizzani et al., 2018). The quality of the relationship is closely related to the quality of woman's sexual functioning and her sexual satisfaction (Gilbert et al., 2010a). Research shows that women can renegotiate their sexual practices if those that were used in the pre-cancer period are not possible or undesirable at this stage (Gilbert, Ussher, \& Perz, 2010b; Gilbert et al., 2010a).

In our research, we have demonstrated a positive relationship between women's sexual satisfaction and their overall satisfaction with the relationship. And although many researchers emphasize the fact that breast cancer treatment increases the risk of sexual dysfunction and decrease in interest and sexual desire in women (Ghizzani et al., 2018), there are also more optimistic reports. One of the studies showed that patients examined 12 months after surgery were generally happy with their relationships and sexually well adjusted, with the partner's emotional support after the surgery playing a crucial role (Kinsinger et al., 2011).

Commenting on our research, we would like to draw attention to yet another interesting result, since it turned out that the time since the first diagnosis and the surgical treatment was an important negative predictor of women's marital satisfaction. This result is consistent with some other results obtained by different researchers, in which it was noted that in a group of women after mastectomy, as time went by (on average, it was about 6 years from the first diagnosis and treatment) there was a decrease in marital satisfaction in comparison with the group of women who underwent breast-conserving surgery (Boostani et al., 2015). It is estimated that $10-40 \%$ of women with breast cancer experience negative changes in their relationships (cf. Rock et al., 2014). However, inconsistencies can be observed in the literature relating to the relationship between the time since the diagnosis, the commencement of treatment and marital satisfaction. Some studies show that the majority of breast cancer patients do not report a decline in quality of their marital relationship (cf. Moreira, Crespo, Pereira, \& Canavarro, 2010). Other studies indicate that the time since the treatment completion is moderately positively related to marital satisfaction (Ptacek, Ptacek, \& Dodge, 1994; cf. Thornton \& Perez, 2007), while yet other studies point to the positive aspects of cancer-related experiences such as greater appreciation of life, changes in priorities, closer relationships, and an increase in positive interactions between partners (Zimmermann, 2015). Moreira et al. (2010), on the basis of a literature review, stated that such experiences become an opportunity for many women to strengthen relationships and feel closer to their partner, which can sometimes even improve the relationship. Some researchers, in turn, emphasize that marital satisfaction after cancer diagnosis is not significantly different from marital satisfaction in the general population (cf. Moreira et al., 2010). However, the conclusions from studies on marital functioning in the general population are neither simple nor unambiguous. Some studies suggest a decrease in marital satisfaction or happiness among middle-aged adults compared to those who are younger or older (see Bookwala, 2012). Our research was dominated by middle-aged women (the mean age was 55 years). Thus, the interpretation of the observed negative relationship between the time since the first diagnosis and the surgical treatment and the marital satisfaction can be twofold: either in terms of the decline of marital satisfaction over the years (as in the case of the general population), or in terms of deterioration of relations between spouses resulting from the couple's difficulties coping with the consequences of breast cancer treatment.

Finally, a few limitations should be taken into account when interpreting the research results. First of all, the relatively small sample of women with breast cancer after mastectomy may limit the generalizability of the results. Secondly, the study was crosssectional and therefore has the disadvantages of all such tests (for example, it does not allow an analysis of the sequence of events). Thirdly, in the sample, there were differences among women in the length of time that had passed since the first diagnosis and the surgical procedure, which undoubtedly differentiates their personal experience and the assessment of the partner as helpful in dealing with the disease and treatment. Therefore, further research is needed to confirm our findings.

In our research we assumed that the depression of women with breast cancer predicts marital dissatisfaction. Even though this assumption is fully justified, it would be worth trying to test a model in which the relationship between depression and marital satisfaction is bidirectional. When testing bidirectional causality, multilevel modelling could be employed to examine both individual and cross-partner effects of depressive symptoms and marital satisfaction. A dyadic perspective (the Actor-Partner Interdependence Model) and phases of illness could be taken into account when investigating the complex nature of the relationship between depressive symptoms in women with breast cancer and marital satisfaction.

In future research it would be desirable to control variables that could potentially have an effect on the post-mastectomy symptoms of depression in women (e.g. negative life circumstances, comorbidity of other chronic diseases, decrease of partner's involvement). Besides the partner's and social support, in the follow-up research it would be interesting to include variables that can influence women's marital 
satisfaction, such as the ability to cope with stress, certain personality dimensions or, in more general terms, personal resources that can affect the positive post-traumatic changes in individuals struggling with cancer (Ogińska-Bulik, 2013, 2018).

\section{CONCLUSIONS}

Our findings support and broaden previous studies that indicate a significant and direct relationship between the partner's acceptance of a woman with breast cancer who underwent mastectomy and her positive evaluation of her marriage. In addition, we have demonstrated the mediating role of both the partner's acceptance and the woman's sense of sexual satisfaction as factors modifying the relationship between female depression (a consequence of the distress associated with the treatment of breast cancer) and her marital satisfaction. Both of these variables played the role of total mediators. This means that, due to the conviction about the acceptance by the partner, depression in women treated for breast cancer ceases to affect marital satisfaction. A similar role was played by woman's sexual satisfaction, which also significantly weakened the relationship between depression and marital satisfaction. The negative relationship between the time since the first diagnosis and surgical treatment and marital satisfaction observed in our research can be considered either as a result of decreasing marital satisfaction over the years (similarly as in the general population), or as an effect of the deterioration of relations between spouses resulting from the couple's difficulties coping with the consequences of breast cancer treatmeFurther research is needed in this area. However, the findings outlined in this study can already constitute helpful tips for clinicians and other health professionals in working with women after mastectomy and their partners.

\section{RefERENCES}

Alacacioglu, A., Dirican, U., \& Yilmaz, I. (2013). Depression and anxiety in cancer patients and their relatives. Medical Oncology, 18, 767-774.

Andysz, A., Najder, A., Merecz-Kot, D., \& Wójcik, A. (2015). Posttraumatic growth in women after breast cancer surgery - preliminary results from a study of Polish patients. Health Psychology Report, 3, 336-344. https://doi.org/10.5114/hpr.2015.52383

Avci, I. A., \& Kumcagiz, H. (2011). Marital adjustment and loneliness status of women with mastectomy and husbands reactions. Asian Pacific Journal of Cancer Prevention, 12, 453-459.

Baglama, B., \& Atak, I. (2015). Posttraumatic growth and related factors among postoperative breast cancer patients. Procedia. Social and Behavioral Sciences, 190, 448-454.

Baron, R. M., \& Kenny, D. A. (1986). The moderatormediator variable distinction in social psychological research: Conceptual, strategic, and statistical considerations. Journal of Personality and Social Psychology, 51, 1173-1182.

Barthakur, M. S., Sharma, M. P., Chaturvedi, S. K., \& Manjunath, S. K. (2017). Body image and sexuality in women survivors of breast cancer in India: Qualitative findings. Indian Journal of Palliative Care, 23, 13-17.

Beach, S. R. H., Sandeen, E. E., \& O’Leary, K. D. (1990). Depression in marriage: A model for etiology and treatment. New York: Guilford Press.

Boeding, S. E., Pukay-Martin, N. D., Baucom, D. H., Porter, L. S., Kirby, J. S., Gremore, T. M., \& Keefe, F. J. (2014). Couples and breast cancer: Women's mood and partners' marital satisfaction predicting support perception. Journal of Family Psychology, 28, 675-683.

Bolger, N., Foster, M., Vinokur, A. D., \& Ng, R. (1996). Close relationships and adjustment to a life crisis: The case of breast cancer. Journal of Personality and Social Psychology, 70, 283-294.

Bookwala, J. (2012). Marriage and the other partnered relationships in middle and late adulthood. In R. Blieszner \& V. H. Bedford (Eds.), Handbook of aging and the family (pp. 91-124). Santa Barbara, CA: ABC-CLIO.

Boostani, H., Hoseini, S. M., Khodadadi, N., \& Froozi, N. (2015). Marital satisfaction in women with breast cancer: A comparison between mastectomy and breast conserved patients. Biomedical \& Pharmacology Journal, 8, 1237-1242.

Brandt-Salmeri, A., \& Przybyła-Basista, H. (2018). Obraz ciała a samoocena kobiet z rakiem piersi rola akceptacji ciała [Body image and self-esteem in women with breast cancer - the role of body acceptance]. Psychoonkologia, 22, 1-10.

Brix, S. A., Bidstrup, P. E., Christensen, J., Rottmann, N., Olsen, A., Tjønneland, A., Johansen, C., \& Dalton, S. O. (2013). Post-traumatic growth among elderly women with breast cancer compared to breast cancer-free women. Acta Oncologica, 52, 345-354.

Bulotiene, G., Veseliunas, J., Ostapenko, V., \& Furmonavicius, T. (2008). Women with breast cancer: relationships between social factors involving anxiety and depression. Archives of Psychiatry and Psychotherapy, 4, 57-62.

Bulsa, M., Rzepa, T., Foszczyńska-Kłoda, M., CzajaBulsa, G., \& Teichert, H. (2002). Stan psychiczny kobiet po mastektomii. Doniesienie z badań [The mental state of women after mastectomy. A study report]. Postępy Psychiatrii i Neurologii, 11, 55-70.

Chybicka, A., \& Karasiewicz, K. (2008). Scale of Assessment of Self-Attractiveness in Relationship - validation research. Polish Journal of Social Science, 3, 159-180.
Depression and marital satisfaction in women after mastectomy 
Cohen, S., \& Wills, T. A. (1985). Stress, social support, and the buffering hypothesis. Psychological Bulletin, 98, 310-357.

Cordero, A., Mur-Villar, N., Sanchez, M., Pimente-Ramirez, M., Garcia-Rillo, A., \& Gomez-Valverde, E. (2015). Breast cancer and body image as a prognostic factor of depression: a case study in México City. Nutrición Hospitalaria, 31, 371-379.

Cordova, M. J., Riba, M. B., \& Spiegel, D. (2017). Posttraumatic stress disorder and cancer. Lancet Psychiatry, 4, 330-338. https://doi.org/10.1016/S22150366(17)30014-7

Brandt-Salmeri, Hanna

Przybyła-Basista

Davila, J., Karney, B. R., Hall, T. W., \& Bradbury, T. N. (2003). Depressive symptoms and marital satisfaction: Within subject associations and the moderating effects of gender and neuroticism. Journal of Family Psychology, 17, 557-570.

Derbis, R., \& Machnik-Czerwik, A. (2016). Adaptation of the Body Image after Breast Cancer Questionnaire in the Polish context: Factorial structure and validity of the scale. Health Psychology Report, 4, 170-187. https://doi.org/10.5114/hpr.2016.56837

Fagundes, C., LeRoy, A., \& Karuga, M. (2015). Behavioral symptoms after breast cancer treatment: A biobehavioral approach. Journal of Personalized Medicine, 5, 280-295.

Fang, S. Y., Chang, H. T., \& Shu, B. C. (2014). Objectified body consciousness, body image discomfort, and depressive symptoms among breast cancer survivors in Taiwan. Psychology of Women Quarterly, 38, 563-574.

Fowler, C., \& Gasiorek, J. (2017). Depressive symptoms, excessive reasurance seeking, and relationship maintenance. Journal of Social and Personal Relationships, 34, 91-113. https://doi.org/10.1177/ 0265407515624265

Ghizzani, A., Bruni, S., \& Luisi, S. (2018). The sex life of women surviving breast cancer. Gynecological Endocrinology, 34, 821-825. https://doi:org/ 10.1080/09513590.2018.1467401

Gilbert, E., Ussher J. M., \& Perz, J. (2010b). Renegotiating sexuality and intimacy in the context of cancer: The experiences of carers. Archives of Sexual Behavior, 39, 998-1009.

Gilbert, E., Ussher, J. M., \& Perz, J. (2010a). Sexuality after breast cancer: A review. Maturitas, 66, 397-407.

Hagedoorn, M., Kuijer, R. G., Buunk, B. P., DeJong, G. M., Wobbes, T., \& Sanderman, R. (2000). Marital satisfaction in patients with cancer: Does support from intimate partners benefit those who need it the most? Health Psychology, 19, 274-282.

Heidari, M., Shahbazi, S., \& Ghodusi, M. (2015). Evaluation of body esteem and mental health in patients with breast cancer after mastectomy. Journal of Mid-life Health, 6, 173-177.

Helgeson, V. S., \& Cohen, S. (1996). Social support and adjustment to cancer: Reconciling descriptive, correlational, and intervention research. Health Psychology, 15, 135-148.
Hopwood, P., Fletcher, I., Lee, A., \& Al Ghazal, S. (2001). A body image scale for use with cancer patients. European Journal of Cancer, 37, 189-197.

Hopwood, P., Lee, A., Shenton, A., Baildam, A., Brain, A., Lalloo, F., Evans, G., \& Howell, A. (2000). Clinical follow-up after bilateral risk reducing ('prophylactic') mastectomy: mental health and body image outcomes. Psycho-Oncology, 9, 462-472.

Izydorczyk, B., Kwapniewska, A., Lizinczyk, S., \& Sitnik-Warchulska, K. (2018). Psychological resilience as a protective factor for the body image in post-mastectomy women with breast cancer. International Journal of Environmental Research and Public Health, 15, 1181. https://doi.org/10.3390/ ijerph15061181

Jemal, A., Siegel, R., Ward, E., Hao, Y., Xu, J., Murray, T., \& Thun, M. J. (2008). Cancer statistics. CA: A Cancer Journal for Clinicians, 58, 71-96.

Juczyński, Z., \& Ogińska-Bulik, N. (2009). Pomiar zaburzeń po stresie traumatycznym - polska adaptacja Zrewidowanej Skali Wydarzeń [Measurement of post-traumatic stress disorder Polish version of Impact Event Scale-Revised]. Psychiatria, 6, 15-25.

Kamińska, M., Ciszewski, T., Kukiełka-Budny, B., Kubiatowski, T., Baczewska, B., Makara-Studzińska, M., Starosławska, E., \& Bojar, I. (2015). Life quality of women with breast cancer after mastectomy or breast conserving therapy treated with adjuvant chemotherapy. Annals of Agricultural and Environmental Medicine, 22, 724-730.

Karabulutlu, E., Mehmet, B., Kerim, Ç., Salim, T., \& Ragibe, K. (2010). Anxiety and Depression in Turkish Patients with Cancer. European Journal of General Medicine, 7, 296-302.

Kinsinger, S. W., Laurenceau, J. P., Carver, C. S., \& Antoni, M. H. (2011). Perceived partner support and psychosexual adjustment to breast cancer. Psychology and Health, 26, 1571-1588.

Koçan, S., \& Gürsoy, A. (2016). Body image of women with breast cancer after mastectomy: A qualitative research. Journal of Breast Health, 12, 145-150.

Koczwara, B., \& Clark, M. M. (2003). A couple with cancer: conflicting wishes, joint decisions. Journal of Clinical Oncology, 21, 174-176.

Li, Q., \& Loke, A. Y. (2014). A literature review on the mutual impact of the spousal caregiver-cancer patients dyads: 'communication', 'reciprocal influence', and 'caregiver-patient congruence'. European Journal of Oncology Nursing, 18, 58-65.

Madhumanti, M., \& Sathiyaseelan, A. (2014). Marital adjustment in women after one year of mastectomy. Global Journal of Biology and Health Sciences, 3, 43-47.

Maly, R. C., Umezawa, Y., Leak, B., \& Silliman, R. A. (2005). Mental Health Outcomes in Older Women with Breast Cancer: Impact of Perceived Family Support and Adjustment. Psycho-Oncology, 14, 535-545. 
Manne, S., Sherman, M., Ross, S., Ostroff, J., Heyman, R. E., \& Fox, K. (2004). Couples' supportrelated communication, psychological distress, and relationship satisfaction among women with early stage breast cancer. Journal of Consulting and Clinical Psychology, 72, 660-670. https://doi. org/10.1037/0022-006X.72.4.660

Manos, D., Sebastian, J., Bueno, M. J., Mateos, N., \& de la Torre, A. (2005). Body image in relation to selfesteem in a sample of Spanish women with earlystage breast cancer. Psicooncologia, 2, 103-116.

Mehnert, A., \& Koch, U. (2007). Prevalence of acute and post-traumatic stress disorder and comorbid mental disorders in breast cancer patients during primary cancer care: a prospective study. Psychooncology, 16, 181-188.

Mehnert, A., \& Koch, U. (2008). Psychological comorbidity and health-related quality of life and its association with awareness, utilization, and need for psychosocial support in a cancer register-based sample of long-term breast cancer survivors. Journal of Psychosomatic Research, 64, 383-391. https:// doi.org/10.1016/j.jpsychores.2007.12.005

Moreira, H., Crespo, C., Pereira, M., \& Canavarro, M. C. (2010). Marital quality among women with breast cancer: The role of marital intimacy and quality of life. Psicooncologia, 7, 61-80.

Moyá, J., Prous, A. C., Fernández, A. S., \& Alonso, Á. (2010). The impact a first episode of major depression has on marital dissatisfaction: Is remission associated with improvement in dissatisfaction? The European Journal of Psychiatry, 24, 46-58.

Ogińska-Bulik, N. (2010). Potraumatyczny rozwój w chorobie nowotworowej - rola prężności [Posttraumatic growth in cancer disease - the role of resiliency]. Polskie Forum Psychologiczne, 15, 125-139.

Ogińska-Bulik, N. (2013). The role of social support in posttraumatic growth in people struggling with cancer. Health Psychology Report, 1, 1-8. https:// doi.org/10.5114/hpr.2013.40464

Ogińska-Bulik, N. (2018). The role of ruminations in the relation between personality and positive posttraumatic changes resulting from struggling with cancer. Health Psychology Report, 6, 296-306. https://doi.org/10.5114/hpr.2019.77176

O'Mahoney, J. M., \& Carroll, R. A. (1997). The impact of breast cancer and its treatment on marital functioning. Journal of Clinical Psychology in Medical Settings, 4, 397-415.

Parnowski, T., \& Jernajczyk, W. (1977). Inwentarz Depresji Becka w ocenie nastroju osób zdrowych i chorych na choroby afektywne [Beck's Depression Inventory in the rating of mood in normal subjects and in patients with affective disturbances]. Psychitaria Polska, 11, 417-421.

Pintado, S. (2017). Self-concept and emotional wellbeing in patients with breast cancer. Revista Iberoamericana de Psicología y Salud, 8, 76-84.
Plopa, M. (2006). Więzi w matżeństwie i rodzinie. Metody badań [Marital and family ties. Research methods]. Kraków: Oficyna Wydawnicza Impuls.

Pruchno, R. A., Wilson-Genderson, M., \& Cartwright, F. P. (2009). Depressive symptoms and marital satisfaction in the context of chronic disease: A longitudinal dyadic analysis. Journal of Family Psychology, 23, 573-584. https://doi.org/10.1037/a0015878

Ptacek, J. T., Ptacek, J. J., \& Dodge, K. L. (1994). Coping with breast cancer from the perspectives of husbands and wives. Journal of Psychosocial Oncology, $12,47-72$.

Rehman, U. S., Gollan, J., \& Mortimer, A. R. (2008). The marital context of depression: research, limitations, and new directions. Clinical Psychology Review, 28, 179-198. https://doi.org/10.1016/j.cpr. 2007.04.007

Reich, M., Lesur, A., \& Perdrizet-Chevallier, C. (2008). Depression, quality of life and breast cancer: A review of the literature. Breast Cancer Research and Treatment, 110, 9-17. https://doi.org/10.1007/ s10549-007-9706-5

Renshaw, K. D., Blais, R. K., \& Smith, T. W. (2010). Components of negative affectivity and marital satisfaction: The importance of actor and partner anger. Journal of Research in Personality, 44, 328334. https://doi.org/101016/j.jrp.2010.03.005

Rock, E. E., Steiner, J. L., Rand, K. L., \& Bigatti, S. M. (2014). Dyadic influence of hope and optimism on patient marital satisfaction among couples with advanced breast cancer. Supportive Care in Cancer, 22, 2351-2359.

Rowland, J. H., Meyerowitz, B. E., Crespi, C. M., Leedham, B., Desmond, K., Belin, T. R., \& Ganz, P. A. (2009). Addressing intimacy and partner communication after breast cancer: a randomized controlled group intervention. Breast Cancer Research and Treatment, 118, 99-111.

Siegel, R. L., Miller, K. D., \& Jemal, A. (2018). Cancer statistics, 2018. CA: A Cancer Journal for Clinicians, $68,7-30$.

Srivastava, V., Mumtaz, A., Anand, K., Shah, A., \& Meena, R. (2016). Study of anxiety among breast cancer patients from North India. Clinical Psychiatry, 2. https://doi.org/10.21767/2471-9854.100017

Stadnicka, G., Pawłowska-Muc, A., Bańkowska, B., \& Sadowska, M. (2014). Jakość życia kobiet po amputacji piersi [Quality of life in women after mastectomy]. European Journal of Medical Technologies, $4,8-14$

Stankiewicz, A., Radziwiłłowicz, W., \& Bidzan, M. (2011). Związek cech osobowości, depresyjności i lęku z przebiegiem leczenia kobiet z nowotworem piersi [Relationships between personality, fear and depression in patients with breast cancer]. Psychoonkologia, 2, 48-54.

Stephanson, E., Delongis, A., Esdaile, J. M., \& Lehman, A. J. (2014). Depressive symptoms and rheu-
Depression and marital satisfaction in women after mastectomy 
matoid arthritis: Spouse empathic responding as a buffer. Arthritis Care and Research, 66, 532-541.

Su, J. A., Yeh, D. C., Chang, C. C., Lin, T. C., Lai, C. H., Hu, P. Y., Ho, Y. F., Chen, V. C. H., Wang, T. N., \& Gossop, M. (2017). Depression and family support in breast cancer patients. Neuropsychiatric Disease and Treatment, 13, 2389-2396.

Svetina, M., \& Nastran, K. (2012). Family relationships and posttraumatic growth in breast cancer patients. Psychiatria Danubina, 24, 298-306.

Anna

Brandt-Salmeri,

Talley, A., Molix, L., Schlegel, R. J., \& Bettencourt, A. (2010). The influence of breast cancer survivors' perceived partner support and need satisfaction on depressive symptoms: A longitudinal analysis. Psychology and Health, 25, 433-449.

Thornton, A. A., \& Perez, M. A. (2007). Interpersonal relationships. In M. Feuerstein (Ed.), Handbook of cancer survivorship (pp. 191-210). New York: Springer.

Weihs, K., Enright, T., Howe, G., \& Simmens, S. J. (1999). Marital satisfaction and emotional adjustment after breast cancer. Journal of Psychosocial Oncology, 17, 33-49.

Wiederman, M. W. (2000). Women's body image self-consciousness during physical intimacy with a partner. Journal of Sex Research, 37, 60-68.

Wimberly, S. R., Carver, C. S., Laurenceau, J. P., Harris, S. D., \& Antoni, M. H. (2005). Perceived partner reactions to diagnosis and treatment of breast cancer: Impact on psychosocial and psychosexual adjustment. Journal of Consulting and Clinical Psychology, 73, 300-311.

Zahlis, E. H., \& Lewis, F. M. (2010). Coming to grips with breast cancer: the spouse's experience with his wife's six month. Journal of Psychosocial Oncology, 8, 79-97.

Zainal, N. Z., Nik-Jaafar, N. R., Baharudin, A., Sabki, Z. A., \& Ng, C. G. (2013). Prevalence of depression in breast cancer survivors: A systematic review of observational studies. Asian Pacific Journal of Cancer Prevention, 14, 2649-2656.

Zawadzki, B., Popiel, A., \& Pragłowska, E. (2009). Charakterystyka psychometryczna polskiej adaptacji Kwestionariusza Depresji BDI-II Aarona T. Becka [Psychometric characteristics of the Polish adapted version of the BDI-II by Aaron T. Beck]. Psychologia - Etologia - Genetyka, 19, 71-95.

Zimmermann, T. (2015). Intimate relationships affected by breast cancer: Interventions for couples. Breast Care, 10, 102-108. 